\title{
Intragenic Recombination and Diversifying Selection Contribute to the Evolution of Downy Mildew Resistance at the RPP8 Locus of Arabidopsis
}

\author{
J ohn M. McDowell, a,1 Murali Dhandaydham, ${ }^{a, 1}$ Terri A. Long, a Mark G. M. Aarts, ${ }^{b}$ Stephen Goff,c \\ Eric B. Holub, and J effery L. Dangl $\left.\right|^{a, e, 2}$ \\ a Department of B iology, C.B. 3280 Coker Hall, University of North Carolina, Chapel Hill, North Carolina 27599-3280 \\ b Department of Molecular Biology, DLO Centre for Plant Breeding and Reproduction Research, Postbus 16, 6700AA, \\ Wageningen, The Netherlands \\ c Biotechnology and Genomics Center, Novartis Crop Protection, Inc., Research Triangle Park, North Carolina $27709-2257$ \\ d Director's Research Group, Horticulture Research International, Wellesbourne, Warwickshire, CV35 9EF, United Kingdom \\ e Curriculum in Genetics and Molecular Biology, C.B. 3280 Coker Hall, University of North Carolina, Chapel Hill, North \\ Carolina 27599-3280
}

\begin{abstract}
Pathogen resistance (R) genes of the NBS-LRR class (for nucleotide binding site and leucine-rich repeat) are found in many plant species and confer resistance to a diverse spectrum of pathogens. Little is known about the mechanisms that drive NBS-LRR gene evolution in the host-pathogen arms race. We cloned the RPP8 gene (for resistance to Peronospora parasitica) and compared the structure of alleles at this locus in resistant Landsberg erecta (Ler-0) and susceptible Columbia (Col-0) accessions. RPP8-Ler encodes an NBS-LRR protein with a putative N-terminal leucine zipper and is more closely related to previously cloned $\mathbf{R}$ genes that confer resistance to bacterial pathogens than it is to other known RPP genes. The RPP8 haplotype in Ler-0 contains the functional RPP8-Ler gene and a nonfunctional homolog, RPH8A. In contrast, the rpp8 locus in Col- 0 contains a single chimeric gene, which was likely derived from unequal crossing over between RPP8-Ler and RPH8A ancestors within a Ler-like haplotype. Sequence divergence among RPP8 family members has been accelerated by positive selection on the putative ligand binding region in the LRRs. These observations indic ate that NBS-LRR molecular evolution is driven by the same mechanisms that promote rapid sequence diversification among other genes involved in non-self-recognition.
\end{abstract}

\section{INTRODUCTION}

A broad range of microorganisms have evolved the ability to use plants as a nutritional resource, and plants in turn have evolved multiple lines of defense against pathogen invasion (Hammond-Kosack and J ones, 1996a). Inducible defenses are mediated through gene-for-gene systems in which the plant carrying a particular resistance $(R)$ gene allele responds to pathogens carrying a matching avirulence (avr) gene (Flor, 1971). Most plants contain large collections of highly specific $\mathrm{R}$ genes, which are thought to encode specialized receptors that recognize avr gene-dependent elicitors (Keen, 1990). If the $\mathrm{R}$ gene or the corresponding avr gene is not functional, then recognition does not occur, defenses are not activated, and the plant is susceptible to infection. Thus, pathogens can circumvent gene-for-gene resistance by alteration or loss of avr genes. This places the

\footnotetext{
${ }^{1}$ These authors contributed equally to this work.

${ }^{2}$ To whom correspondence should be addressed. E-mail dangl@ email.unc.edu; fax 919-962-1625.
}

host under selective pressure to evolve new recognition capabilities. avr gene mutations and deletions occur at high frequency in nature (van Kan et al., 1991; Rohe et al., 1995; Sweigard et al., 1995; J oosten et al., 1997), but the host's response in this evolutionary arms race is not well understood.

Two themes have emerged from recent molecular characterization of $\mathrm{R}$ genes. $\mathrm{R}$ genes are often members of tightly linked multigene families, which can be functionally diversified (Hammond-Kosack and Jones, 1996b). A second, somewhat unexpected generality is that all $R$ genes characterized to date, with one exception (Martin et al., 1993), encode proteins with long stretches of leucine-rich repeats (LRRs) (J ones and J ones, 1996). LRRs are present in a wide variety of proteins and participate in protein-protein interactions and ligand binding (Kobe and Deisenhofer, 1995). Crystal structure analysis has demonstrated that the LRRs of a ribonuclease inhibitor form a solvent-exposed $\beta$ sheet structure that binds the ribonuclease (Kobe and Deisenhofer, 1993). By analogy, LRRs in plant $R$ proteins are thought to bind pathogen-derived signal molecules and thereby mediate 
recognitional specificity (Dixon et al., 1996), although direct biochemical evidence is currently lacking.

Two superfamilies of LRR-encoding pathogen $R$ genes have been defined by putative functional motifs and predicted localization of the encoded proteins (Dangl, 1995). One superfamily, represented by the tomato $\mathrm{Cf}$ genes (for resistance to the fungal pathogen Cladosporium fulvum) (Hammond-Kosack and J ones, 1996b) and the Xa21 gene family in rice (for resistance to the bacterial pathogen Xanthomonas campestris pv oryzae) (Song et al., 1995), encodes proteins that are predicted to be membrane bound and composed primarily of extracytoplasmic LRRs. The Cf R proteins do not contain any recognizable signaling domain, whereas Xa21 contains extracytoplasmic LRRs fused to a cytoplasmic kinase domain.

The second and larger $\mathrm{R}$ gene superfamily (referred to as NBS-LRR) encodes proteins with a predicted nucleotide binding site followed by a variable number of $\mathrm{C}$-terminal LRRs (Bent, 1996). NBS-LRR proteins do not contain a recognizable signal sequence and probably function inside the cell (Leister et al., 1996). Most NBS-LRR genes fall into one of two subclasses based on their N-terminal motifs (Bent, 1996). The TIR-NBS-LRR subclass is defined by an N-terminal region that resembles the cytoplasmic signaling domain of the Toll and interleukin1 transmembrane receptors (Parker et al., 1997). This subclass includes genes that specify resistance to a virus (N in tobacco) (Whitham et al., 1994), fungi (L6 and $M$ in flax) (Lawrence et al., 1995; Anderson et al., 1997), and oomycetes (RPP5, RPP 1A, RPP1B, and RPP1C in Arabidopsis, where RPP signifies resistance to Peronospora parasitica) (Parker et al., 1997; Botella et al., 1998). The second subclass (LZ-NBS-LRR) contains a leucine zipper-like motif in place of the TIR domain and is represented by the genes RPM 1 (Grant et al., 1995), RPS2 (Bent et al., 1994; Mindrinos et al., 1994), and Prf (Salmeron et al., 1996). These genes specify resistance to Pseudomonas syringae pathovars.

Recent comparative analyses of extracytoplasmic LRR gene clusters have provided insight into their evolution. The Cf-4/9 gene cluster contains related but functionally distinct genes that are subject to positive diversifying selection in the LRRs (Parniske et al., 1997). Sequence exchanges appear to occur between linked Cf-4/9 homologs; novel Cf-4/9 haplotypes, which differ in gene copy number, can be generated by unequal crossovers at homologous intergenic regions. Evidence for gene duplications, intragenic recombination, and diversifying selection also has been reported for the Xa21 gene cluster (Song et al., 1997; Wang et al., 1998). Thus, molecular evolution of gene clusters encoding extracytoplasmic LRR-containing $R$ proteins is driven by the same mechanisms that generate diversity in other complex loci involved in non-self-recognition, such as the major histocompatibility complex (MHC) in animals (Dangl, 1992; Parham and Ohta, 1996; Hughes and Yeager, 1997).

Although NBS-LRR genes are widespread in plants and recognize many types of pathogens, little is known about the mode of NBS-LRR gene evolution. The available NBS-LRR sequences are very divergent from each other and provide no evolutionary insight other than definition of the conserved motifs described above. The structural differences between putative extracytoplasmic LRR proteins and NBS-LRR proteins imply that these two $R$ protein superfamilies are biochemically distinct, and it is therefore of interest to determine whether they have evolved by different mechanisms.

We have used the Arabidopsis-P. parasitica (downy mildew) pathosystem for comparative analysis of $R$ gene evolution. $P$. parasitica is a biotrophic oomycete and a prominent natural pathogen of Arabidopsis in Europe (Koch and Slusarenko, 1990; Holub and Beynon, 1996). A large number of Arabidopsis RPP genes have been defined using P. parasitica isolates from natural Arabidopsis populations (Holub et al., 1994; Tör et al., 1994). These genes are functionally polymorphic among Arabidopsis accessions, suggesting that coevolution of host and parasite has been rapid and dynamic. Thus, comparison of allelic variants will provide insight into $R$ gene evolution. The Arabidopsis- $P$. parasitica pathosystem also provides the opportunity to examine $R$ gene evolution in a naturally evolving interaction, thereby avoiding potential loss of genetic diversity from bottlenecks in selective breeding of crop species as well as phylogenetic artifacts caused by forced introgression of genes from wild species.

Four RPP genes recently have been shown to encode members of the TIR-NBS-LRR subclass (Parker et al., 1997; Botella et al., 1998). In contrast, we show in this study that the RPP8 gene is a member of the LZ-NBS-LRR subclass. Furthermore, sequence comparisons of resistant and susceptible RPP8 alleles provide evidence that intragenic recombination and positive selection interact to promote sequence diversification in NBS-LRR R gene evolution.

\section{RESULTS}

\section{Genetic and Physical Definition of the RPP8 Locus}

The RPP 8 gene specifies resistance to the Emco5 isolate of $P$. parasitica in the Arabidopsis accession Landsberg erecta (Ler-0). Emco5 is compatible with accession Columbia-0 (Col-0). Therefore, we used the Dean and Lister Col-0 $\times$ Ler- 0 recombinant inbred (RI) lines (Lister and Dean, 1993) to map RPP8 genetically, as shown in Figure 1. When we used $100 \mathrm{RI}$ lines, resistance to Emco5 segregated as a single locus (RPP8) on chromosome 5 in the interval between Dfr and Lfy. We identified 71 additional Dfr-Lfy recombinants from an additional $198 \mathrm{RI}$ lines, and we used these recombinants to narrow the interval, defining Spl2 and Cral as closer markers on either side of RPP8. Spl2 identified one recombinant centromeric to RPP8, and Cral identified five recombinants telomeric to RPP8 (Figure $1 \mathrm{~A}$ ).

Yeast artificial chromosome (YAC) end probes and genetically anchored molecular markers were used to construct a physical map of the RPP8 interval (Figure 1A). The SpI2 and 

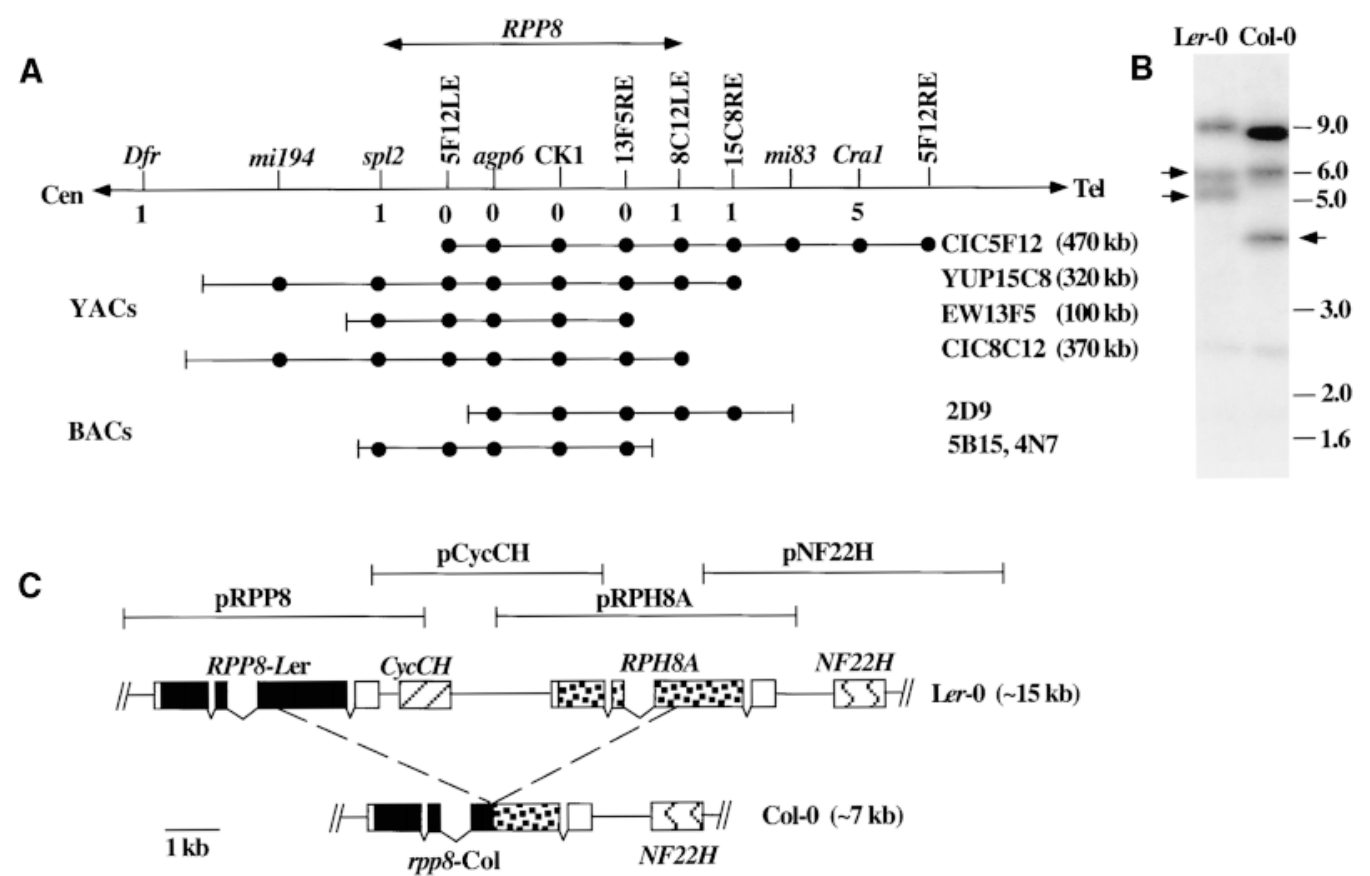

Figure 1. Genetic and Physical Map of the RPP8 Region.

(A) Genetic map of the RPP8 interval. Molecular markers are shown above the line, and the number of recombinants that separate each marker from RPP 8 are shown below the line. The minimum genetic interval of RPP 8 is shown between the arrowheads at top. Dfr, spl2, and Cral are cleaved amplified polymorphic sequence markers. CK1 refers to the restriction fragment length polymorphism (RFLP) shown in (B). The remaining markers are RFLPs derived from yeast artificial chromosome (YAC) ends. YAC and bacterial artificial chromosome (BAC) clones are depicted below the genetic map, with approximate lengths shown at right. YAC clones CIC4E12, CIC6F12, and EW6E5, which also map in the same region, are not shown. Cen, centromeric; Tel, telomeric.

(B) Gel blot of genomic DNA from Col-0 and Ler- 0 that was digested with EcoRV and probed with the CK1 candidate gene fragment at moderate stringency. The RFLP cosegregating with RPP 8 is shown by arrows. The Col- 0 band that comigrates with the doublet in Ler- 0 segregated independently of the doublet. DNA length standards are shown at right in kilobases.

(C) Physical structure of the RPP 8 locus in Ler- 0 and Col- 0 . The Ler- 0 segment represents 15 of the $23 \mathrm{~kb}$ that were sequenced from the $9 \mathrm{~L} 9$ cosmid. Genomic subclones are depicted above the physical map. RPP8-Ler and RPH8A coding sequences are depicted by filled and stippled boxes, respectively, $5^{\prime}$ and $3^{\prime}$ untranslated regions are depicted by open boxes, and introns are represented by diagonal lines. The boxes labeled $\mathrm{CycCH}$ and $\mathrm{NF} 22 \mathrm{H}$ represent regions of homology to rice cyclin $\mathrm{C}$ and a hypersensitive response-inducing gene (NF22) from tobacco, respectively. In Col-0, the region between RPP8-Ler and RPH8A has been deleted, as depicted by the dashed lines.

Cral markers both mapped within the YAC contig, demonstrating that the contig spanned the RPP 8 locus. We genetically mapped four YAC ends as restriction fragment length polymorphisms (RFLPS) to refine further the RPP8 interval. 5F12LE and 13F5RE RFLPs both cosegregated with RPP8, whereas 8 C 12LE and 15C8RE detected one recombinant telomeric to RPP8. The SpI2-8C12LE interval thus defined the smallest possible genetic interval in our mapping population. This genetic distance corresponds to a maximum physical distance of $\sim 100$ to $300 \mathrm{~kb}$ (Figure 1A).

\section{Identification and Mapping of an RPP8 Candidate Gene}

A candidate for the RPP 8 gene (CK1, described by M.G.M. Aarts et al., 1998) was amplified with degenerate poly- merase chain reaction $(P C R)$ primers from conserved $R$ gene motifs. CK1 hypothetically encodes an LRR sequence with $\sim 30 \%$ identity and $40 \%$ similarity to segments of the RPM1 gene and hybridized with a polymorphic multicopy family in both Col-0 and Ler-0 (Figure 1B). We genetically and physically mapped an EcoRV RFLP, which consists of a double band $(\sim 5.5$ to $6 \mathrm{~kb})$ in Ler- 0 and a single $\sim 4.5-\mathrm{kb}$ band in Col-0 (Figure 1B). The Ler- 0 doublet cosegregated with resistance to Emco5 in the subset of RI lines that contained recombinations between Dfr and Lfy. Conversely, the $4.5-\mathrm{kb}$ Col-0 band was always present in Emc05-susceptible RI lines and hybridized with all of the Col-0 YACs and bacterial artificial chromosomes (BACs) spanning rpp8 (Figure 1A). The genetic and physical colocalization of the EcoRV RFLP with the RPP8 phenotype, in combination with its sequence similarity to known $\mathrm{R}$ genes and potential copy 
number polymorphism, implicated it as a candidate gene for RPP 8.

\section{Transgenic Complementation of RPP8 Function}

We isolated genomic cosmid clones containing the EcoRV doublet from Ler- 0 by using the CK1 probe. One cosmid (9L9) contains a $23-\mathrm{kb}$ insert that includes both bands of the doublet. A second cosmid (25M 19), which overlaps with 9L9 over $\sim 17 \mathrm{~kb}$, contains the upper band of the doublet and a fragment of the lower band (data not shown). Both cosmids were transformed into susceptible $\mathrm{Col}-0$, and transgenic $\left(\mathrm{T}_{1}\right)$ seedlings were selected and allowed to set seed. $T_{2}$ progeny from multiple independent transformants were inoculated with Emco5 and assessed for resistance. Complementation experiments are summarized in Table 1 . All 12 tested Col::9L9 transgenic lines segregated $\sim 3: 1$ for resistant to susceptible in the $T_{2}$ generation, which is consistent with a single, dominant transgenic locus conferring Emco5 resistance. At least five of six tested Col::9L9 lines were independent transformants (data not shown). None of the seven tested Col::25M $19 \mathrm{~T}_{2}$ lines displayed resistance to Emco5 (Table 1), suggesting that the lower band of the doublet was necessary for Emco5 resistance. Neither 9L9 nor 25M 19 provided resistance to the Madil or Noco2 isolates of $P$. parasitica (Table 1).

Only one CK1-hybridizing band was detectable in the Col-0 YACs and BACs spanning rpp8 (data not shown),

Table 1. Interaction Phenotypes of Col-0 Transgenic Plants and Ler-0 rpp8 Mutants with P. parasitica Isolates

\begin{tabular}{llll}
\hline Genotype & Emco5 & Madi1 $^{\mathrm{a}}$ & Noco2 $^{\mathrm{a}}$ \\
\hline Col-0::9L9 & $\mathrm{R}$ & $\mathrm{S}$ & $\mathrm{S}$ \\
Col-0::25M 19 & $\mathrm{S}$ & $\mathrm{S}$ & $\mathrm{S}$ \\
Col-0::pRPH8A & $\mathrm{S}$ & & \\
Col-0::pRPP8 & $\mathrm{R}$ & & \\
Col-0::pCYCH & $\mathrm{S}$ & & \\
Col-0::pNF22H & $\mathrm{S}$ & & $\mathrm{R}$ \\
rpp8-1 & $0.9(0.4)^{\mathrm{b}}$ & $\mathrm{R}$ & $\mathrm{R}$ \\
rpp8-2 & $12.6(1.2)^{\mathrm{b}}$ & $\mathrm{R}$ & $\mathrm{R}$ \\
rpp8-3 & $3.0(0.9)^{\mathrm{b}}$ & $\mathrm{R}$ & $\mathrm{R}$ \\
rpp8-4 & $6.5(1.0)^{\mathrm{b}}$ & $\mathrm{R}$ & \\
rpp8-5 & $2.7(0.5)^{\mathrm{b}}$ & & \\
rpp8-6 & $2.3(0.5)^{\mathrm{b}}$ & & $\mathrm{S}$ \\
Col-0 wild type & $16.0(0.9)^{\mathrm{b}}$ & $\mathrm{S}$ & $\mathrm{S}$ \\
Ler-0 wild type & $0.0^{\mathrm{b}}$ & $\mathrm{R}$ & $\mathrm{R}$ \\
\hline
\end{tabular}

${ }^{a} R$, resistant; $S$, susceptible. Four to 12 transgenic lines were assayed for each construct. Consistent phenotypes were observed in each case.

${ }^{b}$ Quantitative disease ratings are expressed as the mean number of sporangiophores per cotyledon from 10 plants, with the standard error shown within parentheses. Quantitative assessments were conducted for three separate inoculations with similar results. suggesting that only one Col- 0 CK1 family member is present in this $>470-\mathrm{kb}$ interval. Furthermore, mapping of other CK1-hybridizing bands demonstrated that no other CK1 family members are closely linked to RPP 8 (described by M.G.M. Aarts et al., 1998). Cosmids containing additional CK1 family members conferred no resistance to any $P$. parasitica isolate in transgenic Col- 0 (data not shown). These results suggest that resistance to Emco5 in Ler is conferred specifically by one member of the CKI gene family.

\section{Two Closely Related Genes Are Present at the RPP8 Locus in Ler-0}

Sequencing of the $9 \mathrm{~L} 9$ cosmid insert revealed two highly similar NBS-LRR genes (Figure 1C). We constructed subclones to separate these two genes (Figure 1C). All of the four lines transgenic for PRPP 8 were completely resistant to Emc05, whereas all of the four lines transgenic for pRPH8A were as susceptible to Emco5 as is wild-type Col-0 (Figure 2A and Table 1). Thus, a single NBS-LRR gene, referred to hereafter as RPP8-Ler, is sufficient to provide Emco5 resistance in the Col- 0 background. The second gene (named RPH8A for RPP8 homolog A) is insufficient for transgenic complementation of resistance to Emco5 in Col-0.

RPP8-Ler and RPH8A are separated by a 3.7-kb segment containing a putative open reading frame with $75 \%$ amino acid similarity to cyclin $\mathrm{C}$ from rice (Figure 1C). A fourth open reading frame $\sim 1 \mathrm{~kb}$ downstream of RPH8A resembles ( $\sim 50 \%$ amino acid similarity) the tobacco gene NF22 (GenBank accession number U66266). NF22 was identified by its ability to induce a hypersenstive response-like reaction when overexpressed (Karrer et al., 1998). Subclones of the NF22 homolog or the cyclin C homolog conferred no resistance to Emco5 in transgenic Col-0 plants (Table 1 ).

The intron-exon structure of RPP8-Ler was deduced by comparison to RPP8 cDNAs and is diagrammed in Figure $1 \mathrm{C}$. The RPP 8 coding sequence contains two introns: intron 1 (129 bp) splits codon 292, and intron 2 (675 bp) splits codon 341. A third intron (123 bp) begins 4 bp downstream of the stop codon in the RPP 8 cDNA. Sequence analysis of 11 independent RPP 8-Ler clones revealed variable polyadenylation sites $\sim 450$ bp downstream of the stop codon. The gene structure of RPH8A could not be confirmed by cDNA comparison because no RPH8A cDNAs were isolated, but it is probably identical because conserved intron-exon border sequences were found at identical locations in the RPH8A coding sequence. Interestingly, the $3^{\prime}$ ends of RPP8-Ler and RPH8A are identical over an 898-bp stretch, from codon 837 to 688 bp downstream of the stop codon (including the intron, 3' untranslated region, and downstream nontranscribed sequence). After this 898-bp stretch, similarity between the two genes is very low. The $5^{\prime}$ flanking sequences of RPP 8-Ler and RPH8A are almost completely dissimilar, except for a 90-bp stretch of $89 \%$ identity, which begins 473 and 692 bp upstream of the RPP8-Ler and RPH8A start codons, respectively. 
A

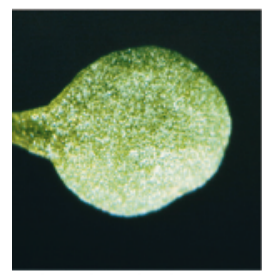

Ler-0 wild type

B

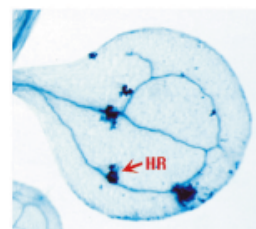

Ler-0 wild type

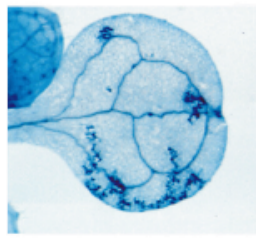

rpp8-2 X Ler-0 F1

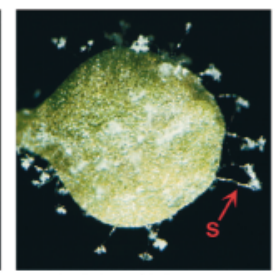

Col-0 wild type

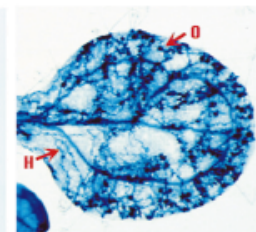

Col-0 wild type

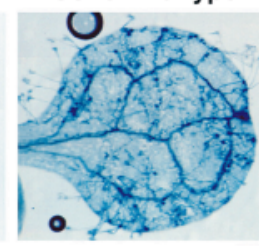

rpp8-2 X Col-0 F1

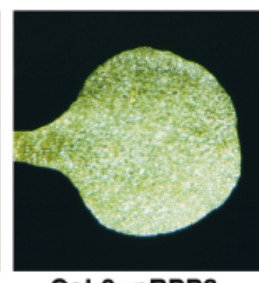

Col-0::pRPP8

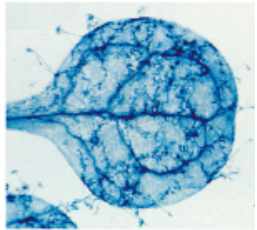

rpp8-2

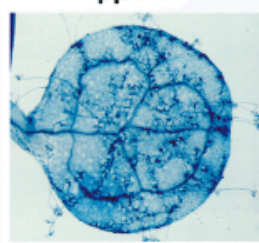

rpp8-2 X rpp8-3 F1
Figure 2. Interaction Phenotypes of Col-0::pRPP8 Transgenic Plants and Ler-0 rpp8 Mutants.

(A) RPP 8 from Ler- 0 confers resistance to Emco5 in transgenic Col- 0 plants. At 7 days after inoculation with Emco5, wild-type Col- 0 cotyledons support heavy asexual sporulation ( $S$, sporangiophores), whereas no sporulation is visible on wild-type Ler-0 or transgenic Col- 0 seedlings containing the pRPP 8 subclone from the $9 L 9$ cosmid. (B) The rpp8-2 mutant in Ler-0 is susceptible to Emco5. The interaction phenotypes of cotyledons from $F_{1}$ progeny of various crosses demonstrate that rpp8-2 is recessive to RPP8-Ler and allelic to rpp8-Col and rpp8-3. Cotyledons were stained at 7 days after inoculation with trypan blue, which is retained by parasite structures $(H$, hyphae; 0 , oospores) and dead host cells (HR).

\section{RPP8 Encodes a Member of the LZ-NBS-LRR Subclass}

Figures 3 and 4 provide the primary structures of hypothetical proteins encoded by RPP8-Ler (906 amino acids), rpp8Col (908 amino acids), and RPH8A (907 amino acids). The latter two genes encode full-length hypothetical proteins that share 92 and $91 \%$ amino acid identity, respectively, with RPP8-Ler (Figures 3 and 4, and Table 3). Several putative functional motifs present in known $\mathrm{R}$ genes are apparent in the encoded proteins (Figures 3 and 4). The C-terminal onethird of each gene is composed of 14 imperfect LRRs, which vary in length from 21 to 29 amino acids. A consensus nucleotide binding site and a hydrophobic domain conserved in all NBS-LRR genes are also apparent. Finally, a putative six-heptad leucine zipper is present near the $\mathrm{N}$ terminus.
This motif clearly places RPP8 in a distinct structural subclass from the other RPP proteins that have been identified. RPP8-Ler is more closely related to the RPM 1 bacterial resistance protein from Arabidopsis (26\% identity and $39 \%$ amino acid similarity) than it is to any other known $\mathrm{R}$ protein. RPP8 has no significant similarity with RPP5, RPP1A, RPP1B, or RPP1C, except in the functional domains that define the putative nucleotide binding site.

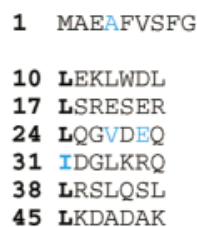

C 52 KHGSDRVRNF LEDVKDLVFD AEDIIESYVL NKLRGEGKGV 92 KKHVRRLARF LTDRHKVASD IEGITKRISD VIGEMQSFGI 132 QQIIDGVRSL SLQERQRVQR EIRQTYPDSS ESDLVGVEQS 172 VKELVGHLVE NDVHQVVSIA GMGGIGKTTL ARQVFHHDLV 212 RRHFDGFAWV CVSQQFTQKH VWQRILQELQ PHDGDI

D

E 276 WKKEDWDVIK AVFPRKRGWK MLLTSRNEGV GIHADPTCLT 316 FRASILNPEE SWKLCERIVF PRRDETEVRL DEEMEAMGKE 356 MVTHCGGLPL AVKVLGGLLA NKHTVPEWKR VSDNIGSQIV 396 GGSCLDDNSL NSVYRILSLS YEDLPTHLKH RFLFLAHFPE 436 YSKISAYDLF NYWAVEGIYD GSTIODSGEY YLEELVRRNL 476 VIADNRYLSS HSKNCQMHDM MREVCLSKAK EENFLQIIKD 516 PTSTSTINAQ SPSRSRRLI HSGKA

$\mathbf{F}$

\begin{tabular}{lll|ll|l}
$\mathbf{5 4 1}$ & FHLL & GHK & NNTKVRS LI & VWDEDFGIRSASV \\
$\mathbf{5 7 0}$ & FHNL & TLL & RVLDLYW & VK & FEGGKLPSS \\
$\mathbf{5 9 5}$ & IGGL & IHL & RYLSLFL AG & VSHLPST \\
$\mathbf{6 1 8}$ & MRNL & KLL & LYLNLSV & NN & KEPIHVPNV \\
$\mathbf{6 4 3}$ & LKEM & IQL & RYLSLPL & KK & DDKTKLE \\
$\mathbf{6 6 6}$ & LGDL & VNL & EFLFGFS & TQ & HSSVTD \\
$\mathbf{6 8 8}$ & LLHM TKL & RYLAVSL & SE & RCNFETLSSS \\
$\mathbf{7 1 4}$ & LREL & RNL & ETLYVLF & SP & EIFMVDYMGEFV \\
$\mathbf{7 4 2}$ & LDHF & IHL & KELGLAV RM & SKIPD \\
$\mathbf{7 6 3}$ & QHQLPPHL & AQIYICN & CR & MEEDPMPI \\
$\mathbf{7 8 8}$ & LEKL LHL & KSVKLTF & KA & FAGRRMVCS \\
$\mathbf{8 1 3}$ & KGGF & TQL & CALEISE SS & ELEEWIVE \\
$\mathbf{8 3 7}$ & EGSM & PCL & RTLTIHD & CE & KLKELPDG \\
$\mathbf{8 6 1}$ & LKYI TSL & KELKIEG MK & REWKEKLVPG \\
$\mathbf{8 8 7}$ & GEDYYKVQHIPDVQFINCDQ & $\mathbf{9 0 6}$
\end{tabular}

Figure 3. Deduced Amino Acid Sequence of RPP8-Ler.

Domains $A$ to $F$ are based on putative functional motifs. Domains $B$ and $D$ contain putative leucine zippers. Domains $C, D$, and $E$ contain the NBS motifs and a conserved hydrophobic domain, shown in boldface. Domain F contains 14 imperfect LRRs defined by the conserved residues shown in boldface. The LRR subdomain XXLXLX$X X X$, which encompasses the putative $\beta$ strand/ $\beta$ turn region identified from the porcine ribonuclease inhibitor crystal structure, is framed between the solid lines. Blue residues represent positions in which either RPH8A or rpp8-Col encodes a different amino acid from RPP8-Ler. Residues in red are different in all three proteins. 


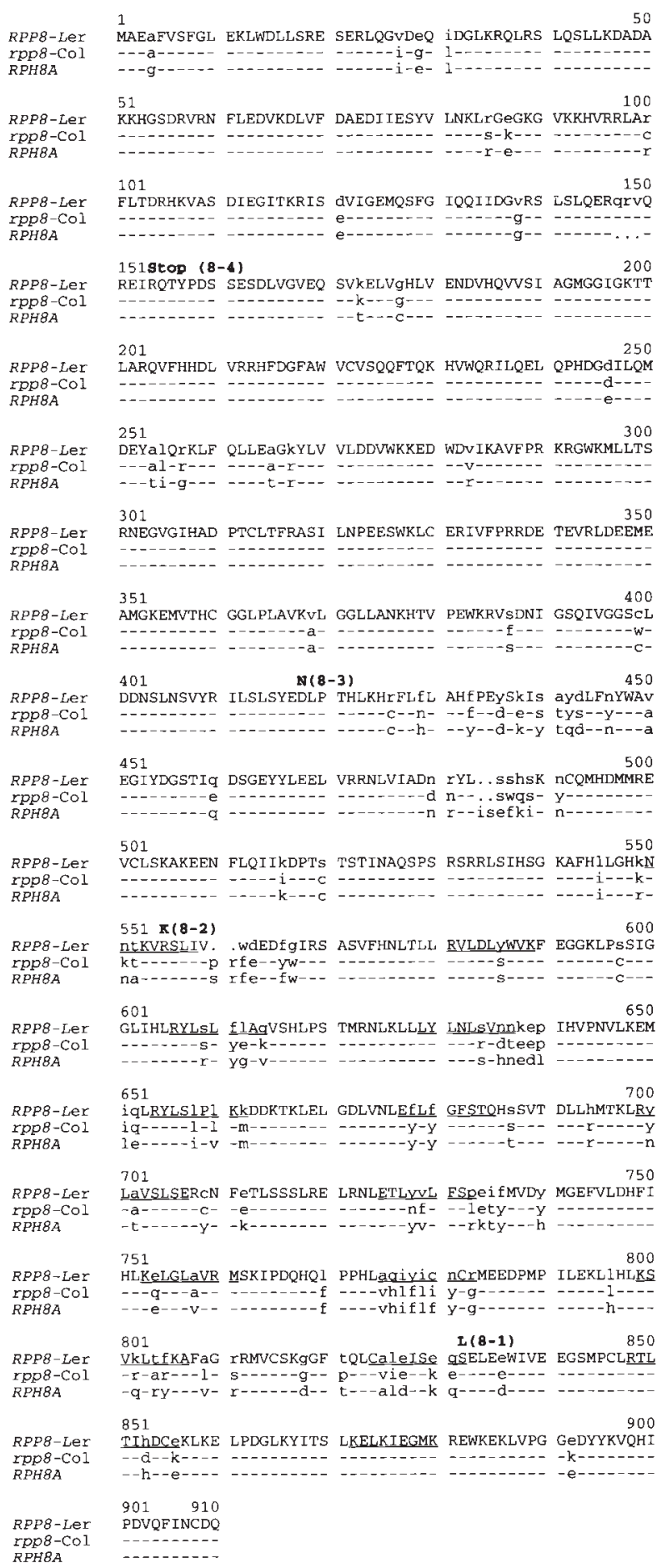

Figure 4. Amino Acid Sequence Alignment of RPP8-Ler, RPH8A, and rpp8-Col.

Dashes represent identical amino acids, and dots represent deletions in RPP8-Ler and rpp8-Col compared with RPH8A. Amino acid substitutions are shown as lowercase letters. Amino acid changes in Ler rpp8 mutants are shown above the RPP8-Ler sequence in bold-

\section{The rpp8 Allele in Col-0 Is a Chimera of Progenitor Genes Related to RPP8-Ler and RPH8A}

As shown in Figure 1C, the structure of the rpp8 locus in Col-0 is dramatically different from the RPP8 locus in Ler- 0 . Only one RPP8 homolog (named rpp8-Col) is present at the Col-0 locus. The 5' flanking sequence of rpp8-Col is almost identical to that of RPP8-Ler, whereas the 3' flanking sequence of rpp8-Col is almost identical to the segment extending from the end of RPH8A to the NF22 homolog (Figure 1C). The segment that separates RPP8 and RPH8A in Ler-0, including the cyclin C homolog, is deleted in Col-0. rpp8-Col thus appears to be derived from a precise in-frame unequal crossover within an ancestral Ler-like RPP8 haplotype.

Seven insertion/deletion sites, shown in Figure 5, were used as landmarks to localize the most likely recombination breakpoint. rpp8-Col shares with RPP 8-Ler a 9-bp insertion (codons 147 to 149) and a 6-bp deletion (codons 484 to 485) relative to the RPH8A sequence (Figures 4 and 5). rpp8-Col also shares four additional indels with RPP8-Ler in intron 2 (Figure 5). rpp8-Col shares a 6-bp insertion with RPH8A, relative to RPP 8-Ler, at codons 560 to 561 . The recombination breakpoint thus appears to be located between codons 486 and 559, which includes the region just upstream of the LRRs as well as part of the first LRR (Figures 3 and 4). Interestingly, most of the indels encompass short direct repeats (Figure 5), which suggests that they could have been generated by transposon insertion and subsequent excision.

The pattern of nucleotide polymorphisms between RPP8Ler, RPH8A, and rpp8-Col is very complicated, as shown in Figure 6. We observed a lack of consistent sequence affiliation, based on shared nucleotide polymorphisms, between any pair of homologs. Instead, the three RPP 8 homologs exhibit a patchwork pattern of affiliations in their coding sequences. For example, the majority of polymorphisms (23 of 39 ) in the first 1000 bp support an affiliation between RPP8Ler and rpp8-Col, which is consistent with the hypothesis that the 5' end of rpp8-Col was derived from an RPP8-Lerlike ancestor. Similarly, the majority of $3^{\prime}$ polymorphisms support an affiliation between rpp8-Col and RPH8A. However, there are segments of contiguous polymorphisms that support different affiliations. For example, nucleotides 130 to 301 contain seven polymorphisms that affiliate RPP8-Ler with RPH8A rather than rpp8-Col. This suggests that a recent exchange occurred between the two Ler-0 genes. Alternatively, this affiliation could reflect the accumulation of contiguous point mutations in the Col- 0 allele. Comparisons with other RPP8 homologs are necessary to distinguish accurately between these possibilities.

face. The XXLXLXXXX motifs are underlined. The corresponding nucleotide sequences have GenBank accession numbers AF089710 and AF089711 for RPP8-Ler and rpp8-Col, respectively. 


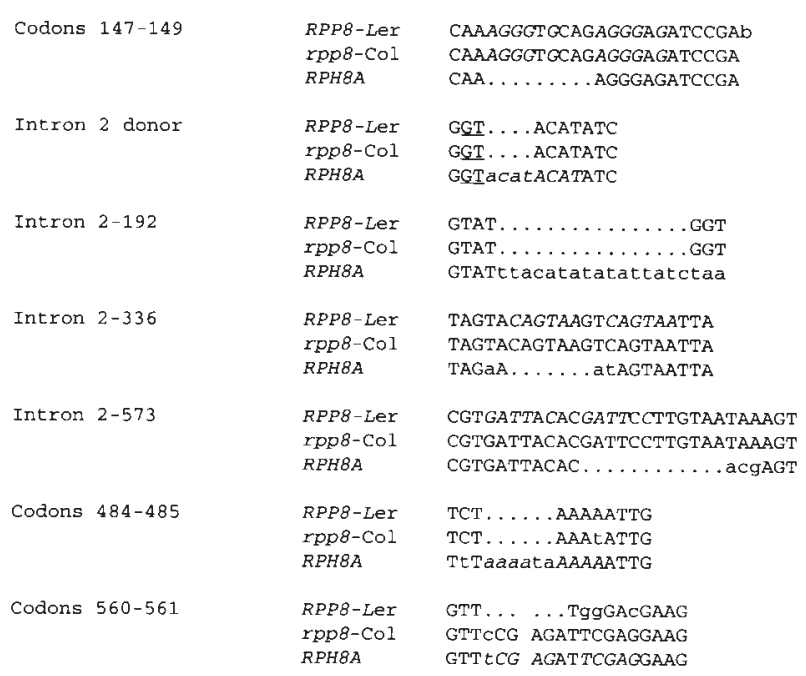

Figure 5. Location and Sequence of Insertion/Deletion Sites in RPP8-Ler, rpp8-Col, and RPH8A.

Codon positions are numbered according to the multiple alignment in Figure 4. Intron positions are numbered from the first nucleotide of intron 2 in RPP8-Ler. Direct repeats are emphasized by italics. Nucleotide substitutions are indicated by lowercase letters. Dots indicate gaps. The intron 2 splice donor site is underlined.

Several of the LRR-encoding segments are extremely divergent among the three genes (Figures 4 and 6 ). The degree of divergence among the LRRs is variable, with LRRs 11 and 12 exhibiting the highest divergence and LRRs 3,10 , 13, and 14 exhibiting the highest degree of conservation. Perhaps the divergent LRRs are directly involved in recogni- tion specificity, whereas the conserved LRRs play a structural role. Two highly variable regions also are apparent outside the LRRs (amino acid residues 432 to 442 and 480 to 489). They do not fall within any recognizable functional motif. We predict that these regions define a new set of functionally relevant residues.

\section{Analysis of rpp8 Mutants in Ler-0}

We isolated six independent rpp8 mutants from a screen of mutagenized Ler- 0 plants. Disease ratings of all mutants are shown in Table 1, and the phenotype of the rpp8-2 mutant is presented in Figure $2 \mathrm{~B}$. The six mutants supported different levels of Emco5 sporulation, suggesting that they represent a series of alleles with mutations of differing severity. Although the levels of Emco5 growth varied somewhat between experiments, rpp8-2 was generally the most susceptible mutant, whereas rpp8-1 exhibited the weakest susceptibility phenotype. Typically, only 20 to $40 \%$ of rpp8-1 cotyledons produced sporangiophores. Each mutant retained wild-type levels of resistance to the Madil (resistance provided by RPP21) and Noco2 (RPP5) isolates. None of the mutants exhibited any obvious developmental phenotype.

Results from genetic analysis of the rpp8 mutants are summarized in Table 2. $F_{1}$ progeny from backcrosses of all six mutants to Ler-0 were resistant to Emco5 (Table 2 and Figure $2 \mathrm{~B}$ ), demonstrating that the mutations were recessive. Trypan blue staining of backcross $F_{1}$ plants revealed occasional trails of necrotic host cells in the cotyledons (Figure $2 B$ ), suggestive of a slightly delayed defense response. This phenomenon was also observed in $F_{1}$ progeny from a cross of wild-type Col- $0 \times$ Ler- 0 (data not shown), suggesting that

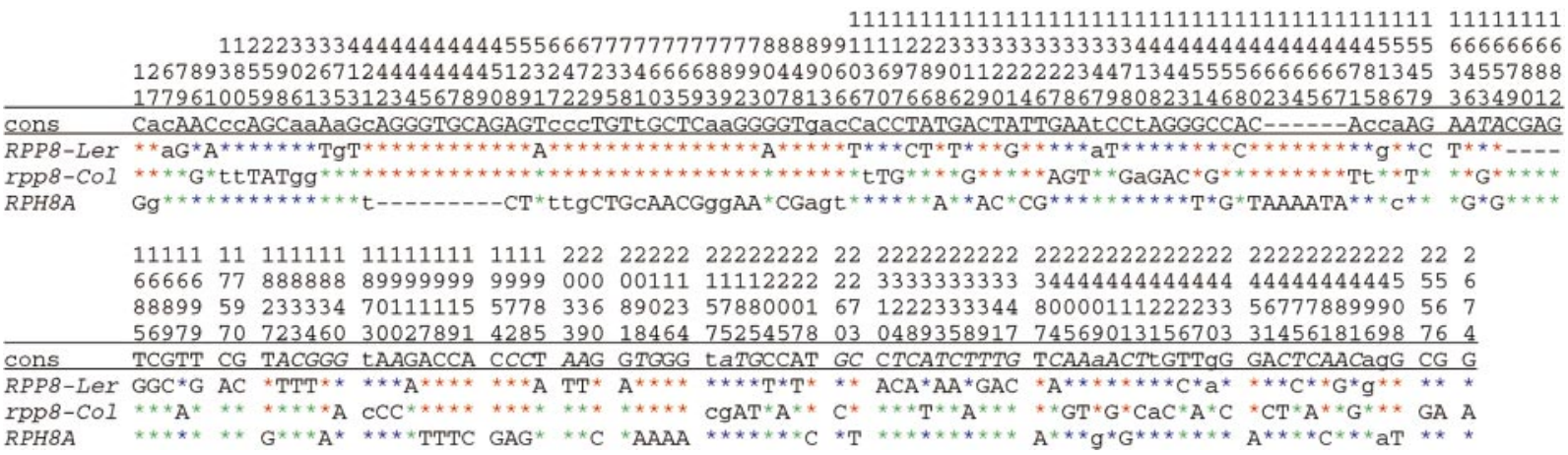

Figure 6. Patchwork Distribution of Nucleotide Polymorphisms between RPP8-Ler, rpp8-Col, and RPH8A Coding Sequences.

Polymorphic sites that distinguish the three genes are shown. Nucleotide positions, beginning from the start codon, are shown above the lines. Nucleotide positions for which all three genes are identical or for which each gene has a different nucleotide are omitted. A consensus (cons) sequence (two of three) is shown between the lines. Residues that conform to the consensus are represented by stars, and silent nucleotide substitutions are shown in lowercase letters. Gaps are represented by dashes. Colors indicate sequence affiliations based on shared polymorphisms. The 14 LRRs are separated by spaces, whereas nucleotides encoding amino acids in the XXLXLXXXX motif are shown by italics in the consensus sequence. 
RPP8-Ler is not completely dominant with respect to rpp8$\mathrm{Col} . \mathrm{F}_{2}$ progeny from the backcrosses of rpp8-2 and rpp8-3 to Ler- 0 segregated $\sim 3$ resistant: 1 susceptible, which is consistent with a single recessive mutation. $F_{2}$ progeny from the rpp8- $1 \times$ Ler- 0 backcross did not segregate any individuals that supported sporulation. This most likely reflects the very weak effect of the rpp8-1 mutation, as suggested by the weak and inconsistent Emco5 growth in the rpp8-1 M3 seedlings described above.

Outcrosses of all of the six mutants to wild-type Col-0 as well as three intermutant crosses yielded susceptible $F_{1}$ progeny (Figure 2B and Table 2). Because RPP 8 is the only locus for Emco5 resistance that segregates between Col- 0 and Ler- 0 , the observed lack of complementation in $F_{1}$ progeny of these crosses strongly suggests that all seven mutations are in RPP8. $F_{2}$ segregation ratios from three tested outcrosses to Col- 0 were consistent with this hypothesis. A significant proportion of $\mathrm{F}_{2}$ progeny from the rpp8- $1 \times \mathrm{Col}-0$ cross did not support sporulation, most likely because of the weak effect of the rpp8-1 mutation. $F_{2}$ progeny from the intermutant crosses also segregated for disease-free individuals. This could reflect the additive effect of two partially functional mutations. Chi-square analysis (Table 2) strongly contradicts the hypothesis that the mutations are in unlinked second site loci (predicted 9 resistant:7 susceptible segregation in outcross and intermutant $F_{2}$ populations).

For further confirmation that these mutations are in the RPP8 gene, we compared the rpp8 coding sequence from four mutants with the wild-type RPP8-Ler sequence. In rpp8-1, a C-to-T mutation in codon 827 caused an S-to-L substitution in LRR12 (Figure 4). In rpp8-2, a G-to-A mutation in codon 553 caused an R-to-K substitution in LRR 1 . In rpp8-3, a G-to-A mutation in codon 418 caused a D-to-N substitution. In rpp8-4, a C-to-T mutation in codon $151 \mathrm{cre-}$ ated a stop codon. These sequence alterations confirm that the $R$ gene candidate is indeed RPP 8 .

\section{Nucleotide Substitution Patterns Suggest That Positive Selection Has Been Acting on RPP8}

We determined that RPP 8 is under positive selection for amino acid diversification by comparing nonsynonymous $\left(\mathrm{K}_{\mathrm{a}}\right)$ and synonymous $\left(\mathrm{K}_{\mathrm{s}}\right)$ nucleotide substitutions in differ-

Table 2. Genetic Analysis of Ler-0 rpp8 Mutants

\begin{tabular}{|c|c|c|c|c|c|}
\hline \multirow[b]{2}{*}{ Cross } & \multicolumn{2}{|l|}{$\mathrm{F}_{1}$} & \multicolumn{2}{|l|}{$\mathrm{F}_{2}$} & \multirow[b]{2}{*}{$\chi^{2}$ (1 degree of freedom) } \\
\hline & $\mathrm{R}^{\mathrm{a}}$ & $S^{b}$ & $\mathrm{R}$ & $\mathrm{S}$ & \\
\hline \multicolumn{6}{|l|}{ Backcross } \\
\hline Ler-0 $\times$ rpp8-1 & 10 & 0 & 40 & 0 & $13.3(\mathrm{P}<0.005)^{c}$ \\
\hline Ler-0 $\times$ rpp8-2 & 9 & 0 & 54 & 15 & $0.4(0.5<\mathrm{P}<0.9)^{\mathrm{C}}$ \\
\hline Ler-0 0 rpp $8-3$ & 3 & 0 & 46 & 12 & $0.6(0.5<P<0.9)^{c}$ \\
\hline Ler-0 × rpp8-4 & 5 & 0 & & & \\
\hline Ler-0 × rpp8-5 & 22 & 0 & & & \\
\hline Ler-0 $\times$ rpp8- 6 & 21 & 0 & & & \\
\hline Ler- $0 \times$ Col-0 & 11 & 0 & 35 & 14 & $0.3(0.5<\mathrm{P}<0.9)^{\mathrm{C}}$ \\
\hline \multicolumn{6}{|l|}{ Outcross } \\
\hline Col-0 0 rpp8-1 & 0 & 22 & 15 & 13 & $0.1(0.5<\mathrm{P}<0.9)^{\mathrm{d}}$ \\
\hline Col-0 $\times$ rpp8-2 & 0 & 26 & 2 & 96 & $117.0(\mathrm{P}<0.005)^{\mathrm{d}}$ \\
\hline Col-0 × rpp8-3 & 0 & 16 & 0 & 35 & $45.0(\mathrm{P}<0.005)^{\mathrm{d}}$ \\
\hline Col-0 $\times$ rpp8-4 & 0 & 16 & 0 & 21 & $27.0(\mathrm{P}<0.005)^{\mathrm{d}}$ \\
\hline Col- $0 \times$ rpp8-5 & 1 & 16 & & & \\
\hline Col- $0 \times$ rpp $8-6$ & 0 & 10 & & & \\
\hline \multicolumn{6}{|l|}{ Intercross } \\
\hline rрp8-1 × rрp8-2 & 0 & 2 & 8 & 22 & $10.7(P<0.005)^{d}$ \\
\hline rpp8-1 $\times$ rpp8-3 & 1 & 6 & & & \\
\hline rpp8-1 $\times$ rpp8-4 & 1 & 11 & 10 & 23 & $9.0(\mathrm{P}<0.005)^{\mathrm{d}}$ \\
\hline rрp8-2 2 rрp8-3 & 0 & 17 & 6 & 27 & $19.4(P<0.005)^{d}$ \\
\hline rрp8-2 $\times$ rрp8-6 & 0 & 4 & & & \\
\hline грp8- $4 \times$ грp8-2 & 0 & 11 & 3 & 13 & $9.1(\mathrm{P}<0.005)^{\mathrm{d}}$ \\
\hline rрp8-4 $\times$ rpp8-3 & 1 & 8 & 6 & 34 & $27.7(\mathrm{P}<0.005)^{d}$ \\
\hline
\end{tabular}


ent segments of the rpp8-Col, RPP8-Ler, and RPH8A protein coding regions. In most cases in which evolution is conservative, the number of synonymous substitutions greatly exceeds that of nonsynonymous substitutions, leading to $a K_{a} / K_{s}$ ratio $<1$. $A K_{a} / K_{s}$ ratio $>1$ indicates selection for amino acid diversification (Kreitman and Akashi, 1995).

Much of amino acid divergence among the three RPP8 family members was concentrated in a subdomain of the LRRs (XX[L]X[L]XXXX), where leucine, isoleucine, or valine residues are found at the conserved positions designated by an $L$ (Figures 3 and 4 ). This motif encompasses a predicted $\beta$ strand/ $\beta$ turn region in which hydrophobic side chains at the conserved positions are buried in the core, and the nonconserved, interstitial residues (designated by $\mathrm{X}$ ) are solvent exposed (Dixon et al., 1996; J ones and J ones, 1996). Calculations of $K_{a}$ and $K_{s}$ (Table 3 ) support the hypothesis that positive selection is acting to diversify putative solventexposed residues. For example, $K_{a}$ in the $X X(L) X(L) X X X X$ codons was $15.8 \%$ between rpp8-Col and RPP8-Ler, whereas $\mathrm{K}_{\mathrm{s}}$ was only $7.8 \%\left(\mathrm{~K}_{\mathrm{a}} / \mathrm{K}_{\mathrm{s}}=2.0\right)$. In the remainder of the coding sequence, excluding the $X X(L) X(L) X X X X$ codons, $K_{a}$ was fivefold lower, and the $K_{a} / K_{s}$ ratio was 0.8 , indicating a more conservative mode of evolution. A similar trend was apparent in the other two pairwise comparisons (Table 3).

\section{DISCUSSION}

Plants may have an inherent disadvantage in the gene-forgene arms race, because loss-of-function mutations in pathogen avr genes are sufficient to disarm gene-for-gene resistance. In contrast, the host must respond with a corresponding gain of function (recognition), and accumulation of point mutations in preexisting $R$ genes alone may not provide sufficient structural diversity for novel resistance specificities to evolve in a timely fashion. Below, we discuss the implications of our results that are relevant to this conundrum.

\section{Structurally Distinct NBS-LRR Subclasses Can Function in P. parasitica Resistance}

It seems likely that novel $\mathrm{R}$ genes are recruited from preexisting $\mathrm{R}$ genes. Genes at the $\mathrm{L}$ and $\mathrm{M}$ loci are highly related to each other, and the $\mathrm{Cf}$ genes in tomato have very similar structural features. Based on these precedents, one might predict that RPP 8 is a member of the TIR-NBS-LRR subclass, like RPP5 and the RPP 1 family members. However, RPP8 encodes an LZ-NBS-LRR protein and is most closely related to the RPM 1 bacterial $R$ gene, demonstrating that the TIR-NBS-LRR and the LZ-NBS-LRR subclasses can function in resistance to $P$. parasitica. Similarly, the $X a 1$ NBS-LRR gene and the Xa21 extracytoplasmic LRR gene specify resistance to different isolates of the same bacterial
Table 3. Pairwise $K_{a}$ and $K_{s}$ and Nucleotide and Amino Acid Homology

\begin{tabular}{llrlll}
\hline Comparison & & Framed $^{a}$ & Nonframed $^{b}$ & Homologyc $^{c}$ & $\%$ \\
\hline RPP8-Ler/rpp8-Col & $\mathrm{K}_{\mathrm{a}}$ & 15.8 & 2.8 & nt id & 96 \\
& $\mathrm{~K}_{\mathrm{s}}$ & 7.8 & 3.5 & aa id & 92 \\
& $\mathrm{~K}_{\mathrm{a}} / \mathrm{K}_{\mathrm{s}}$ & 2.0 & 0.8 & aa sim & 94 \\
RPP8-Ler/RPH8A & $\mathrm{K}_{\mathrm{a}}$ & 11.9 & 3.3 & nt id & 96 \\
& $\mathrm{~K}_{\mathrm{s}}$ & 4.1 & 4.3 & aa id & 91 \\
& $\mathrm{~K}_{\mathrm{a}} / \mathrm{K}_{\mathrm{s}}$ & 2.9 & 0.8 & aa sim & 94 \\
rpp8-Col/RPH8A & $\mathrm{K}_{\mathrm{a}}$ & 13.0 & 3.1 & nt id & 96 \\
& $\mathrm{~K}_{\mathrm{s}}$ & 5.9 & 5.2 & aa id & 91 \\
& $\mathrm{~K}_{\mathrm{a}} / \mathrm{K}_{\mathrm{s}}$ & 2.2 & 0.6 & aa sim & 93
\end{tabular}

a These values represent the percentage of divergence between the two indicated genes in codons encoding the XXLXLXXXX motif in the 14 LRRs. These residues are framed in Figure 3 by vertical bars. $K_{a}$ represents nonsynonymous divergence; $K_{s}$ represents synonymous divergence.

b The percentage of divergence between the indicated genes over the entire protein coding sequence, except for codons that encode the framed XXLXLXXXX motifs.

c Determined over the entire length of the protein coding sequence. ${ }^{\mathrm{d}} \mathrm{nt}$, nucleotide; aa, amino acid; id, identity; sim, similarity.

pathogen of rice (Yoshimura et al., 1998). These observations suggest that plants can recruit a wide range of $\mathrm{R}$ proteins to recognize structurally diverse elicitors from the same pathogen. This is likely to be a key adaptive mechanism, in view of the apparent ease with which pathogens can alter or discard certain avr genes (van Kan et al., 1991; Rohe et al., 1995; Sweigard et al., 1995; J oosten et al., 1997).

Recent genetic evidence suggests that RPP8-mediated resistance may operate through a different signaling pathway from RPP1 and RPP5. The Arabidopsis eds1 (for enhanced disease susceptibility) mutation abolishes the function of several RPP genes, including RPP 5 and RPP 1; however, eds 1 has little or no effect on RPP8 function (N. Aarts et al., 1998). Similarly, the ndr1 mutation, which partially inactivates several RPP genes and completely inactivates the Arabidopsis LZ-NBS-LRR bacterial $R$ genes, does not affect RPP8 (N. Aarts et al., 1998). RPP 8 is the only cloned Arabidopsis $R$ gene that does not require either NDR 1 or EDS 1 for function. RPP 8 may therefore define a novel resistance pathway, or alternatively, NDR1 and EDS1 could be functionally redundant in RPP8-mediated resistance. We are currently constructing lines to test these possibilities.

\section{A Novel rpp8 Haplotype Was Generated by an Unequal Crossover between Linked Genes}

Genetic analyses of R gene clusters, such as Rp1 in maize and $M$ in flax, have indicated that recombination between 
repeated sequences in $\mathrm{R}$ gene clusters is a critical mechanism in R gene evolution (reviewed in Ellis et al., 1997; Hulbert, 1997), and the chimeric structure of the rpp8-Col allele adds to a growing body of molecular data that supports this proposal. Intra-allelic recombinants have been discovered in mutational screens at the M and RPP5 loci (Anderson et al., 1997; Parker et al., 1997). These recombinant alleles arose from ectopic recombination between LRR-encoding modules that caused expansions or contractions in LRR copy number, thereby inactivating the gene. Intragenic recombination also has been proposed to occur within a 5' region that is highly conserved between genes in the Xa21 cluster, resulting in "promoter swaps" with minimal alterations in the coding sequences (Song et al., 1997). Finally, expansions and contractions in gene copy number have been observed to occur in the Cf-4/9 complex by unequal crossing over between homologous intergenic regions (Parniske et al., 1997). The structure of rpp8-Col expands on these observations: rpp8-Col was generated by unequal crossing over between linked, nonallelic genes, it encodes a chimeric protein that differs dramatically from both progenitors, and it was present in at least one natural Arabidopsis population from which the Col-0 accession was derived. The observations that recombination can produce coding sequence chimeras, promoter swaps, and expansion or contraction in gene number and LRR copy number collectively underscore the role of recombination as a potent and versatile force in $\mathrm{R}$ gene evolution.

The functional roles of rpp8-Col and RPH8A are currently unknown. Neither gene is sufficient for resistance to Emco5 in Col-0, but both genes encode predicted full-length proteins. The nonrandom pattern of substitutions in $\beta$ strand $/ \beta$ turn LRR-encoding motifs of both genes suggest that they are functional and remain under selection. We did not find RPH8A cDNAs among the 25 that were isolated, but rpp8Col is expressed, as evidenced by complete identity to the Col-0 expressed sequence tag clone T14073. Therefore, it seems likely that these genes recognize currently undefined pathogens, and experiments are under way to define their functions genetically.

It is also possible that the rpp8-Col and RPH8A genes are obsolete or superfluous. A potential analogy may exist in the MHC, which contains functional class $1 a$ antigen presentation genes as well as class $1 \mathrm{~b}$ genes, which evolved from class la genes by duplication (Klein and O'hUigin, 1994). Some class $1 \mathrm{~b}$ genes are functional, whereas others are expressed at reduced levels and appear to be evolving into nonexpressed pseudogenes. Class 1 MHC genes are thought to undergo turnover through cycles of birth and death as inactive or obsolete genes are supplanted by more efficient copies arising from duplication and divergence (Nei and Hughes, 1992). This process also may operate in plant disease resistance loci, which typically contain duplicated genes with unknown functions (Martin et al., 1994; Anderson et al., 1997; Wang et al., 1998). A significant fraction of these genes could be "molecular fossils" arising from gene turn- over during the host-pathogen arms race. Nonfunctional $\mathrm{R}$ gene homologs may still play an important role, however, as repositories of sequence variation, as is seen among class 1 MHC genes (Hughes, 1995). Indeed, close relatives of RPP 8Ler and RPH8A served as sequence donors when rpp8-Col was generated.

\section{RPP8 Sequence Diversity Arises from Positive Selection}

The divergence between the Col- 0 and Ler-0 RPP 8 alleles is much higher than is divergence among other Arabidopsis alleles (typically $<0.01 \%$ ) (Bergelson et al., 1998). Our analysis of nucleotide substitution patterns suggests that the divergence among RPP 8 family members has been accelerated by positive diversifying selection. Clear evidence for positive selection in molecular evolution has rarely been observed (Kreitman and Akashi, 1995). Interestingly, the majority of genes that appear to be under selection for protein diversification are involved in host-pathogen interactions (Endo et al., 1996). Members of the Cf-4/9 and Xa21 extracellular LRR gene families are under positive selection in the LRR subdomain that is predicted to form a $\beta$ strand/ $\beta$ turn structure (reviewed in J ones and J ones, 1996), and RPP 8 appears to be evolving in an analogous fashion. The fact that two of four sequenced rpp8 mutations are missense substitutions in the XXLXLXXXX motif underscores the functional importance of this domain. It appears that both superfamilies of LRR disease resistance proteins are subject to diversifying selection, potentially for altered ligand binding capabilities in the LRRs. Interestingly, the divergence among the RPP 8 family members is concentrated in a slightly longer motif than in the Cf- $4 / 9$ homologs (XXLXLXX) (Parniske et al., 1997). This possibly reflects adaptations for interactions with structurally dissimilar ligands.

What mechanisms generate the mutations upon which selection acts? Point substitutions are undoubtedly a primary source; however, we found it intriguing that most of the insertion/deletion sites among the three genes, including three indels that encompassed two or three codons, comprise direct repeats of varying degeneracies (Figure 5). This direct repeat structure suggests target site duplication and subsequent imprecise excision of a transposable element(s). Perhaps transposon insertions occurred in RPP 8 immediately after the RPP8-Ler/RPH8A duplication, allowing one homolog to compensate for loss of the other until the transposon was excised. Periods of decreased pathogen pressure also could provide windows of opportunity for transposon insertions (or other sequence rearrangements) to accumulate at no cost to the plant. Regardless of whether the RPP 8 indels were generated by transposons, their presence suggests alternative mutational mechanisms that augment diversification from point substitutions.

Recombination and gene conversion also may have generated sequence diversity at RPP8. Although these two mechanisms cannot create nucleotide substitutions, they 
can reassort existing mutations and cause amino acid substitutions by creating novel codons at recombination breakpoints, as seen in the Cf-4/9 complex (Parniske et al., 1997). The region of complete identity at the $3^{\prime}$ end of RPP8-Ler and RPH8A is suggestive of a recent gene conversion or double crossover. The patchwork pattern of nucleotide polymorphisms among the three RPP 8 family members also suggests that sequence exchanges have occurred during their evolution. Strong evidence for sequence exchanges among MHC genes exists, and theoretical simulations of $\mathrm{MHC}$ evolution have suggested that gene conversion is particularly important for the acquisition of polymorphism under conditions of weak selection (Parham and Ohta, 1996). This may be particularly significant in interactions with biotrophic plant pathogens in which penalties to the host are subtle (Holub and Beynon, 1996).

In combination with other recent comparative analyses of $R$ gene structure, our results have established clear mechanistic parallels between the evolution of the two R gene superfamilies and other loci that determine the outcome of interactions. A growing body of data suggests that genes mediating coevolutionary self- and non-self-interactions are subject to a mode and tempo of evolution that differ dramatically from most other types of genes. Future studies expanding our understanding of the interplay between mutation, recombination, and selection in the generation of novel pathogen $R$ genes should provide insights of broad academic and agricultural significance.

\section{METHODS}

\section{Emco5 Derivation and Pathogenicity Tests}

The Peronospora parasitica isolate Emco5 was intentionally isolated for the purpose of cloning the RPP8 allele from Arabidopsis thaliana Landsberg erecta (Ler-0) (Holub and Beynon, 1996). RPP 8 was defined initially in Ler- 0 by mapping a locus involved in recognition of the isolate Emoy2 by using recombinant inbred (RI) lines from a cross between Ler-W100 (Ler carrying nine phenotypic markers) and Wassilewskija (Ws-0) (Reiter et al., 1992). However, detailed mapping of RPP 8 was difficult in this cross because segregation was complicated by the presence of two additional R genes: RPP1 from Ws- 0 on chromosome 3 and RPP 4 from Ler-W100 on chromosome 4. The Ler $\times$ Columbia (Col-0) RI mapping population could not be used to map RPP 8 because Col-0 also carries a functional RPP4 allele. Consequently, a series of "baiting host lines" carrying a functional RPP 4 allele from either Ler- 0 or Col- 0 were used to select natural recombinant variants that had lost the presumed ATR4 gene. This screen was initiated with the natural oospore (sexual inoculum) population from which Emoy2 was originally derived. Emco5 was eventually isolated using a Ler- $0 \times$ Col-0 RI line (LC175) carrying a Ler-0 RPP 4 allele and a Col-0 RPP 8 allele. The asexual inoculum from this isolate was used to confirm that it was compatible with both Col- 0 and Ws- 0 and was detected by a single RPP locus from Ler- 0 in the two available RI mapping populations. This locus was closely linked to the phenotypic marker TT3 in the Ler-W100 $\times$ Ws-0 RI population that defined the RPP8 locus for Emoy2 resistance and cosegregated with agp6 in the Ler- $0 \times$ Col-0 RI population.

Pathogenicity tests and mutant screens were conducted by spraying 7-day-old seedlings with a suspension of asexual inoculum ( $5 \times$ $10^{4}$ conidiosporangia $\mathrm{mL}^{-1}$ ). Seedlings were then covered with a transparent dome to maintain high humidity and to contain the isolate throughout the experiment. Seedlings were grown for 7 days at 16 to $18^{\circ} \mathrm{C}$ with an 8 -hr photoperiod in a Percival Scientific growth chamber (Boone, lowa). P. parasitica growth was assessed visually at 7 days after inoculation by counting sporangiophores on both sides of the cotyledon and classifying plants as either $\mathrm{N}$ (no sporangiophores), L (1 to 10 sporangiophores), M (11 to 19 sporangiophores), or $\mathrm{H}$ (20 or more sporangiophores). To calculate the mean sporangiophore production shown in Table 1, we used actual numbers ( 0 to 10$)$ for $N$ and $L$ cotyledons and assigned values of 15 (M) and $20(\mathrm{H})$. Hyphal growth was assessed by staining inoculated seedlings with lactophenol-trypan blue (Koch and Slusarenko, 1990).

\section{Identification and Sequencing of rpp8 Mutants}

We mutagenized Ler- 0 seeds with $0.15 \%$ ethyl methanesulfonate for $8 \mathrm{hr} . \mathrm{M}_{2}$ seed was collected from lots of $\sim 50 \mathrm{M}_{1}$ plants. We inoculated 1500 to 2000 7-day-old $M_{2}$ seedlings from each lot with Emco5 and visually screened for asexual sporulation 7 days later. We screened $35 \mathrm{M}_{2}$ lots and identified Emco5-susceptible seedlings from nine lots. Mutants were rescued by treatment with a 1:400 dilution of Ridomil ( $0.1 \mathrm{~g} \mathrm{~L}^{-1}$ metalaxyl; Novartis Ltd., Basel, Switzerland) and transferred to a $16-\mathrm{hr}$ photoperiod at $23^{\circ} \mathrm{C}$. Three mutants exhibited very inconsistent resistance phenotypes and are not described.

We used Ler-0 plants with the ttg marker in this screen to distinguish rogue seeds or outcross contaminants visually. In addition, we tested DNA from each mutant with a set of cleaved amplified polymorphic sequences and simple sequence length polymorphism markers from throughout the genome that distinguished polymorphisms between Ler- 0 and two Emco5-compatible accessions, Col-0 and Ws-0. A Ler-0 pattern was observed for every marker tested in each mutant (data not shown), thereby demonstrating that the mutants were derived from the Ler- 0 background.

We determined the sequence of the mutant Ler rpp8 alleles by polymerase chain reaction (PCR) amplification and direct sequencing of the entire PCR product. Multiple amplification products were sequenced to check for misincorporations during the amplification. We designed PCR primers based on the sequence variation that exists between RPP8-Ler and RPH8A to amplify specifically the RPP8Ler gene. Gene specificity of the primer sets was confirmed using pRPP 8 and pRPH8A as controls. Primer sequences will be provided upon request.

\section{Yeast and Bacterial Artificial Chromosome Manipulation}

Yeast artificial chromosome (YAC) clones that hybridized with markers Dfr and mi83 were kindly provided by R. Schmidt (Max Delbrück Laboratory, Cologne, Germany) and C. Dean (J ohn Innes Centre, Norwich, UK) and assembled into a contig by hybridization with known nearby markers and YAC ends. The YAC ends were cloned by vectorette PCR (Matallana et al., 1992). TAMU bacterial artificial chromosome (BAC) clones (Choi et al., 1995) hybridizing with the $15 \mathrm{C} 8 \mathrm{RE}$ and Spl2 markers were identified, and their integrity was 
confirmed by DNA gel blotting with several markers that span the contig.

\section{cDNA and Genomic Clone Isolation}

Two Ler-0 cDNA libraries (Parker et al., 1997) were kindly provided by M. Coleman (V ohn Innes Centre). One library was size selected for inserts $>1.8 \mathrm{~kb}$. A total of $\sim 1.8$ million plaque-forming units were screened with the $\mathrm{CK} 1$ probe at $65^{\circ} \mathrm{C}$ in $2 \times$ Denhardt's solution $(1 \times$ Denhardt's solution is $0.02 \%$ Ficoll, $0.02 \% \mathrm{PVP}$, and $0.02 \% \mathrm{BSA}$ ). Filters were washed at $65^{\circ} \mathrm{C}$ in $2 \times \mathrm{SSC}(1 \times \mathrm{SSC}$ is $0.15 \mathrm{M} \mathrm{NaCl}$ and $0.015 \%$ sodium citrate). Twenty-five clones that gave signals of varying intensity were purified. Sequence was obtained from both ends of each clone, and the clone that had the longest insert was completely sequenced. The $9 \mathrm{~L} 9$ and $25 \mathrm{M} 19$ cosmids were obtained by screening a Ler- 0 genomic DNA library in the pCLD04541 binary cosmid vector (kindly provided by M. Botella, J ohn Innes Centre), as described above. Cosmid DNA was extracted by standard alkaline lysis procedures, and restriction digest patterns of each cosmid were compared with Ler-0 genomic DNA on gel blots to check for rearrangements in the insert.

\section{RPP8 Subclones}

Fragments of the $9 L 9$ cosmid were subcloned directly into binary plasmid vectors by standard procedures. pRPP 8 contains a 5488 -bp EcoRI fragment that includes the entire RPP8-Ler coding sequence as well as $679 \mathrm{bp}$ of the $5^{\prime}$ flanking sequence and $1288 \mathrm{bp}$ of the $3^{\prime}$ flanking sequence. pRPH8A contains a 5672-bp EcoRI fragment that includes the entire RPH8A coding sequence, 1334 bp of the $5^{\prime}$ sequence, and $815-b p$ of the $3^{\prime}$ sequence. The cyclin $C$ homolog was contained on a 4321-bp Sacl subclone (2826 bp of the $5^{\prime}$ sequence and $639 \mathrm{bp}$ of the $3^{\prime}$ sequence). The NF22 homolog was contained on a 6576-bp Sacl fragment ( $>2 \mathrm{~kb}$ of both the $5^{\prime}$ and $3^{\prime}$ sequences). The $\mathrm{CyCH}$ and NF22H subclones are in the PGPTV-Kan binary vector (Becker et al., 1992). pRPP8 and pRPH8A are in PBAR1, which was derived from $p G P T V$-Bar by replacing the $\beta$-glucuronidase gene with the polylinker from pBluescript SK + (Stratagene, La J olla, CA) (B. Holt, D. Boyes, and J.L. Dangl, unpublished data).

\section{Plant Transformation}

Binary clones were transformed into Agrobacterium tumefaciens GV3101 by electroporation. Tetracycline at $12.5 \mathrm{mg} \mathrm{mL}^{-1}$ was not a reliable selection for transformed Agrobacterium, but kanamycin at $50 \mathrm{mg} \mathrm{mL}^{-1}$ worked consistently. We transformed plants using the vacuum infiltration method (Bechtold et al., 1993). We extracted cosmid DNA from an aliquot of each Agrobacterium culture used for transformation and checked for insert rearrangements by DNA gel blotting. Plants transformed with pGPTV-Kan were selected on Murashige and Skoog (Gibco BRL, Grand Island, NY) medium with $50 \mathrm{mg} \mathrm{mL}^{-1}$ kanamycin. pBarl transformants were selected by spraying seedlings at 5,6 , and 7 days after germination with a solution of $0.01 \%$ BASTA (200 g L-1 glufosinate ammonium; AgrEvo USA, Wilmington, DE) and $0.01 \%$ Silwet L- 77 (Lehle Seeds, Round Rock, TX). Plants that survived this selection were sprayed again at 14 and 15 days after germination.

\section{DNA Sequencing}

To obtain the Ler- 0 sequence, we fragmented the $9 L 9$ cosmid and shotgun subcloned $\sim 1$-kb fragments into the $\mathrm{M} 13$ vector. Recombinant M 13 clones that contained Ler-0 DNA were identified by hybridization and sequenced with the M13 forward primer. These random sequences were assembled into contigs, and gaps were filled by primer walking. To determine the Col-0 sequence, we isolated two contiguous, RPP8-hybridizing, Bglll subclones from the 2D9 BAC that spanned RPP 8. We obtained most of the sequence from both inserts with a collection of primers derived from the Ler- 0 sequence. Gaps were filled by primer walking.

Sequence similarity searches were conducted using the BLAST program with default settings (Altschul et al., 1990). Conceptual translations, pairwise comparisons, and multiple alignments were performed with default settings using the Translate, Gap, and Pileup programs of the software package, version 9.1, from the Genetics Computer Group (Madison, WI). Nonsynonymous $\left(\mathrm{K}_{\mathrm{a}}\right)$ and synonymous $\left(K_{s}\right)$ substitutions were calculated using the Genetics Computer Group Diverge program, which corrects for multiple hits and unequal rates of transitions versus transversions. Residues at the position designated by an $L$ in the $X X(L) X(L) X X X X$ motif were omitted from the calculations of $K_{a}$ and $K_{s}$, based on the rationale that they are under selection for conservation of function (Parniske et al., 1997). Polymorphic sites were displayed with the Sequence Output program (B.G. Spratt, University of Sussex, Brighton, UK).

\section{ACKNOWLEDGMENTS}

We gratefully acknowledge the following contributions: Miguel Botella, Mark Coleman, and J onathan J ones for providing Ler- 0 genomic and cDNA libraries; Guillermo Cardon for providing the Spl2 sequence; Canan $\mathrm{C}$ an and Patricia Chimot for assistance with $\mathrm{P}$. parasitica isolate characterization and confirmation of pathology data; Claire Lister, Caroline Dean, and Renate Schmidt for assistance with genetic and physical mapping; and lan Crute, Ben Holt, Susanne Kjemtrup, and Rheinhard Kunze for providing helpful comments on the manuscript. This work was supported by grants from the U.S. Department of Agriculture National Research Initiative Competitive Grants Program (to J.L.D.), the U.K. Biotechnology and Biological Sciences Research Council (to E.B.H.), and The Netherlands Technology Foundation (to M.G.M.A.). J.M.M. was supported by a postdoctoral fellowship from the National Institutes of Health.

Received J une 23, 1998; accepted September 11, 1998.

\section{REFERENCES}

Aarts, M.G.M., te Lintel Hekkert, B., Holub, E.B., Beynon, J .L., Stiekema, W.J ., and Pereira, A. (1998). Identification of R-gene homologous DNA fragments genetically linked to disease resistance loci in Arabidopsis thaliana. Mol. Plant-Microbe Interact. 11, 251-258.

Aarts, N., Metz, M., Holub, E., Staskawicz, B.J ., Daniels, M.J ., and Parker, J.E. (1998). Different requirements for EDS1 and 
NDR 1 by disease resistance genes define at least two R genemediated pathways in Arabidopsis. Proc. Natl. Acad. Sci. USA 95, 10306-10311.

Altschul, S.F., Gish, W., Miller, W., Meyers, E.W., and Lipman, D.J . (1990). Basic local alignment search tool. J. Mol. Biol. 215, 403-410.

Anderson, P.A., Lawrence, G.J., Morrish, B.C., Ayliffe, M.A., Finnegan, E.J ., and Ellis, J.G. (1997). Inactivation of the flax rust resistance gene $M$ associated with loss of a repeated unit within the leucine-rich repeat coding region. Plant Cell 9, 641-651.

Bechtold, N., Ellis, J ., and Pelletier, G. (1993). In planta Agrobacterium-mediated gene transfer by infiltration of Arabidopsis thaliana plants. C. R. Acad. Sci. Ser. III Sci. Vie 316, 1194-1199.

Becker, D., Kemper, E., Schell, J ., and Masterson, R. (1992). New plant binary vectors with selectable markers located proximal to the left T-DNA border. Plant Mol. Biol. 20, 1195-1197.

Bent, A.F. (1996). Plant disease resistance genes: Function meets structure. Plant Cell 8, 1757-1771.

Bent, A.F., Kunkel, B.N., Dahlbeck, D., Brown, K.L., Schmidt, R., Giraudat, J ., Leung, J ., and Staskawicz, B.J . (1994). RPS2 of Arabidopsis thaliana: A leucine-rich repeat class of plant disease resistance genes. Science 265, 1856-1860.

Bergelson, J., Stahl, E., Dudek, S., and Kreitman, M. (1998). Genetic variation within and among populations of Arabidopsis thaliana. Genetics 148, 1311-1323.

Botella, M.A., Parker, J .E., Frost, L.N., Bittner-Eddy, P.D., Beynon, J .L., Daniels, M.J ., Holub, E.B., and J ones, J .D.G. (1998). Three genes of the Arabidopsis RPP1 complex resistance locus recognize distinct Peronospora parasitica avirulence determinants. Plant Cell 10, 1847-1860.

Choi, S., Creelman, R.A., Mullet, J .E., and Wing, R.A. (1995). Construction and characterization of a bacterial artificial chromosome library of Arabidopsis thaliana. Plant Mol. Biol. 13, 124-128.

Dangl, J .L. (1992). The major histocompatibility complex a la carte: Are there analogies to plant disease resistance genes on the menu? Plant J . 2, 3-11.

Dangl, J .L. (1995). Pièce de résistance: Novel classes of plant disease resistance genes. Cell 80, 363-366.

Dixon, M.S., J ones, D.A., Keddie, J.S., Thomas, C.M., Harrison, K., and J ones, J .D.G. (1996). The tomato Cf-2 disease resistance locus comprises two functional genes encoding leucine-rich repeat proteins. Cell $\mathbf{8 4}$, 451-459.

Ellis, J., Lawrence, G., Ayliffe, M., Anderson, P., Collins, N., Finnegan, J ., Frost, D., Luck, J ., and Pryor, T. (1997). Advances in the molecular genetic analysis of the flax-flax rust interaction. Annu. Rev. Phytopathol. 35, 271-291.

Endo, T., Ikeo, K., and Gojobori, T. (1996). Large-scale search for genes upon which positive selection may operate. Mol. Biol. Evol. 13, 685-690.

Flor, H.H. (1971). Current status of the gene-for-gene concept. Annu. Rev. Phytopathol. 9, 275-296.

Grant, M.R., Godiard, L., Straube, E., Ashfield, T., Lewald, J., Sattler, A., Innes, R.W., and Dangl, J .L. (1995). Structure of the Arabidopsis RPM 1 gene enabling dual specificity disease resistance. Science 269, 843-846.

Hammond-Kosack, K.E., and J ones, J .D.G. (1996a). Resistance gene-dependent plant defense responses. Plant Cell 8, 1773-1791.
Hammond-Kosack, K.E., and J ones, J .D.G. (1996b). Plant disease resistance genes. Annu. Rev. Plant Physiol. Plant Mol. Biol. 48, 575-607.

Holub, E.B., and Beynon, J.L. (1996). Symbiology of mouse ear cress (Arabidopsis thaliana) and oomycetes. Adv. Bot. Res. 24, 228-273.

Holub, E.B., Beynon, J .L., and Crute, I.R. (1994). Phenotypic and genotypic characterization of interactions between isolates of Peronospora parasitica and accessions of Arabidopsis thaliana. Mol. Plant-Microbe Interact. 7, 223-239.

Hughes, A.L. (1995). Origin and evolution of HLA class I pseudogenes. Mol. Biol. Evol. 12, 247-258.

Hughes, A.L., and Yeager, M. (1997). Molecular evolution of the vertebrate immune system. Bioessays 19, 777-786.

Hulbert, S.H. (1997). Structure and evolution of the Rpl complex conferring rust resistance in maize. Annu. Rev. Phytopathol. 35, 293-310.

J ones, D.A., and J ones, J.D.G. (1996). The roles of leucine rich repeats in plant defences. Adv. Bot. Res. Adv. Plant Pathol. 24, 90-167.

J oosten, M.H.A.J., Vogelsang, R., Cozijnsen, T.J., Verberne, M.C., and De Wit, P.J.G.M. (1997). The biotrophic fungus Cladosporium fulvum circumvents $\mathrm{Cf}-4$-mediated resistance by producing unstable AVR4 elicitors. Plant Cell 9, 367-379.

Karrer, E.E., Beachy, R.N., and Holt, C.A. (1998). Cloning of tobacco genes that elicit the hypersensitive response. Plant Mol. Biol. 36, 681-690.

Keen, N.T. (1990). Gene-for-gene complementarity in plant-pathogen interactions. Annu. Rev. Genet. 24, 447-463.

Klein, J ., and O'hUigin, C. (1994). The conundrum of nonclassical histocompatibility complex genes. Proc. Natl. Acad. Sci. USA 91, 6251-6252.

Kobe, B., and Deisenhofer, J . (1993). Crystal structure of porcine ribonuclease inhibitor, a protein with leucine rich repeats. Nature 366, 751-756.

Kobe, B., and Deisenhofer, J. (1995). Proteins with leucine rich repeats. Curr. Opin. Struct. Biol. 5, 409-416.

Koch, E., and Slusarenko, A. (1990). Arabidopsis is susceptible to infection by a downy mildew fungus. Plant Cell 2, 437-445.

Kreitman, M., and Akashi, H. (1995). Molecular evidence for natural selection. Annu. Rev. Ecol. Syst. 26, 403-422.

Lawrence, G.J., Finnegan, E.J., Ayliffe, M.A., and Ellis, J.G. (1995). The L6 gene for flax rust resistance is related to the Arabidopsis bacterial resistance gene RPS2 and the tobacco viral resistance gene N. Plant Cell 7, 1195-1206.

Leister, R.T., Ausubel, F.M., and Katagiri, F. (1996). Molecular recognition of pathogen attack occurs inside of plant cells in plant disease resistance specified by the Arabidopsis genes RPS2 and RPM 1. Proc. Natl. Acad. Sci. USA 93, 15497-15502.

Lister, C., and Dean, C. (1993). Recombinant inbred lines for mapping RFLP and phenotypic markers in Arabidopsis thaliana. Plant J. 4, 745-750.

Martin, G.B., Brommonschenkel, S.H., Chunwongse, J., Frary, A., Ganal, M.W., Spivey, R., Wu, T., Earle, E.D., and Tanksley, S.D. (1993). Map-based cloning of a protein kinase gene conferring disease resistance in tomato. Science 262, 1432-1436. 
Martin, G.B., Frary, A., Wu, T., Brommonschenkel, S., Chunwongse, J., Earle, E.D., and Tanksley, S.D. (1994). A member of the tomato P to gene family confers sensitivity to fenthion resulting in rapid cell death. Plant Cell 6, 1543-1552.

Matallana, E., Bell, C.J ., Lu, P.J ., and Ecker, J .E. (1992). Genetic and physical linkage of the Arabidopsis genome: Methods for anchoring yeast artificial chromosomes. In Methods in Arabidopsis Research, C. Koncz, N.-H. Chua, and J. Schell, eds (Singapore: World Scientific), pp. 144-169.

Mindrinos, M., Katagiri, F., Yu, G.-L., and Ausubel, F.M. (1994) The A. thaliana disease resistance gene RPS2 encodes a protein containing a nucleotide-binding site and leucine-rich repeats. Cell 78, 1089-1099.

Nei, M., and Hughes, A. (1992). Balanced polymorphism and evolution by the birth and death process in the MHC loci. In Proceedings of the Eleventh Histocompatibility Workshop and Conference, K. Tsuji, M. Aizawa, and T. Suzuki, eds (Oxford, UK: Oxford University Press), pp. 27-38.

Parham, P., and Ohta, T. (1996). Population biology of antigen presentation by MHC class I molecules. Science 272, 67-74.

Parker, J .E., Coleman, M.J ., Szabò, V., Frost, L.N., Schmidt, R., van der Biezen, E.A., Moores, T., Dean, C., Daniels, M.J ., and J ones, J .D.G. (1997). The Arabidopsis downy mildew resistance gene RPP 5 shares similarity to the Toll and interleukin- 1 receptors with $\mathrm{N}$ and L6. Plant Cell 9, 879-894.

Parniske, M., Hammond-Kosack, K.E., Golstein, C., Thomas, C.M., J ones, D.A., Harrison, K., Wulff, B.B.H., and J ones, J.D.G. (1997). Novel disease resistance specificities result from sequence exchange between tandemly repeated genes at the $\mathrm{Cf}$ 4/9 locus of tomato. Cell 91, 821-832.

Reiter, R.S., Williams, J.G.K., Feldman, K.A., Rafalski, J.A., Tingey, S.V., and Scolnik, P.A. (1992). Global and local genome mapping in Arabidopsis thaliana by using recombinant inbred lines and random amplified polymorphic DNAs. Proc. Natl. Acad. Sci. USA 89, 1477-1481.

Rohe, M., Gierlich, A., Hermann, H., Hahn, M., Schmidt, B., Rosahl, S., and Knogge, W. (1995). The race-specific elicitor, NIP1, from the barley pathogen, Rhynchosporium secalis, determines avirulence on host plants of the Rrs1 resistance genotype. EMBO J . 14, 4168-4177.
Salmeron, J.M., Oldroyd, G.E.D., Rommens, C.M.T., Scofield, S.R., Kim, H.-S., Lavelle, D.T., Dahlbeck, D., and Staskawicz, B.J . (1996). Tomato Prf is a member of the leucine-rich repeat class of plant disease resistance genes and lies embedded within the P to kinase gene cluster. Cell 86, 123-133.

Song, W.-Y., Wang, G.-L., Chen, L.-L., Kim, H.-S., Pi, L.-Y., Holsten, T., Gardner, J., Wang, B., Zhai, W.-X., Zhu, L.-H., Fauquet, C., and Ronald, P.C. (1995). A receptor kinase-like protein encoded by the rice disease resistance gene, Xa21. Science 270, 1804-1806.

Song, W.-Y., Pi, L.-Y., Wang, G.-L., Gardner, J ., Holsten, T., and Ronald, P.C. (1997). Evolution of the rice Xa21 disease resistance gene family. Plant Cell 9, 1279-1287.

Sweigard, J .A., Carroll, A.M., Kang, S., Farrall, L., Chumley, F.G., and Valent, B. (1995). Identification, cloning, and characterization of PWL2, a gene for host species specificity in the rice blast fungus. Plant Cell 7, 1221-1233.

Tör, M., Holub, E.B., Brose, E., Musker, R., Gunn, N., Can, C., Crute, I.R., and Beynon, J.L. (1994). Map positions of three loci in Arabidopsis thaliana associated with isolate-specific recognition of Peronospora parasitica. Mol. Plant-Microbe Interact. 7, 214-222.

van Kan, J.A.L., van den Ackerveken, G.F.J.M., and de Wit, P.G.J .M. (1991). Cloning and characterization of CDNA of avirulence gene avr9 of the fungal pathogen Cladosporium fulvum, causal agent of tomato leaf mold. Mol. Plant-Microbe Interact. 4, 52-59.

Wang, G.-L., Ruan, D.-L., Song, W.-Y., Sideris, S., Chen, L., Pi, L.-Y., Zhang, S., Zhang, Z., Fauquet, C., Gaut, B.S., Whalen, M.C., and Ronald, P.C. (1998). Xa21D encodes a receptor-like molecule with a leucine-rich repeat domain that determines racespecific recognition and is subject to adaptive evolution. Plant Cell 10, 765-779.

Whitham, S., Dinesh-Kumar, S.P., Choi, D., Hehl, R., Corr, C., and Baker, B. (1994). The product of the tobacco mosaic virus resistance gene $\mathrm{N}$ : Similarity to Toll and the interleukin-1 receptor. Cell 78, 1101-1115.

Yoshimura, S., Yamanouchi, U., Katayose, Y., Toki, S., Wang, Z.X., Kono, I., Kurata, N., Yano, M., Iwata, N., and Sasaki, T. (1998). Expression of Xal, a bacterial blight-resistance gene in rice, is induced by bacterial inoculation. Proc. Natl. Acad. Sci. USA 95, 1663-1668. 
Intragenic Recombination and Diversifying Selection Contribute to the Evolution of Downy Mildew Resistance at the RPP8 Locus of Arabidopsis

John M. McDowell, Murali Dhandaydham, Terri A. Long, Mark G. M. Aarts, Stephen Goff, Eric B. Holub and Jeffery L. Dangl

Plant Cell 1998;10;1861-1874

DOI 10.1105/tpc.10.11.1861

This information is current as of July 22, 2020

References

Permissions

eTOCs

CiteTrack Alerts

Subscription Information
This article cites 53 articles, 23 of which can be accessed free at: /content/10/11/1861.full.html\#ref-list-1

https://www.copyright.com/ccc/openurl.do?sid=pd_hw1532298X\&issn=1532298X\&WT.mc_id=pd_hw1532298X

Sign up for eTOCs at:

http://www.plantcell.org/cgi/alerts/ctmain

Sign up for CiteTrack Alerts at:

http://www.plantcell.org/cgi/alerts/ctmain

Subscription Information for The Plant Cell and Plant Physiology is available at: http://www.aspb.org/publications/subscriptions.cfm 